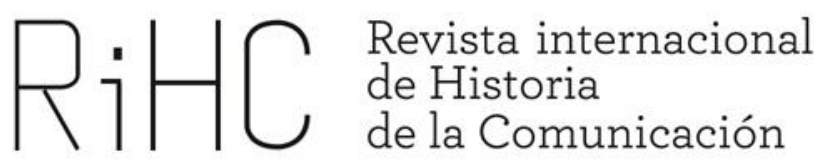

\title{
A LA TRANSICIÓN ESPAÑOLA A TRAVÉS DE PROGRAMAS DE LA RADIO SUIZA DE HABLA ITALIANA - RSI (1975-1978)
}

DOI: http://dx.doi.org/10.12795/RiHC.2013.i01.10

\section{Moisés Prieto López \\ Universidad de Zúrich \\ moises.prieto@hist.uzh.ch}

Resumen: El presente trabajo es un estudio sobre el tratamiento de la Transición española por parte de la Radio suiza de habla italiana (Radio Svizzera di Lingua Italiana - RSI), partiendo de la crisis del régimen en octubre de 1975 hasta el referéndum sobre la constitución en diciembre de 1978. La duración de las emisiones, su estructura y participantes muestran un fuerte interés por parte del periodismo radiofónico suizo de los años setenta por los sucesos españoles. A través del análisis de cinco emisiones se puede averiguar la mirada pendiente y apasionada de los profesionales de la RSI y la imagen de un país en cambio.

Palabras clave: radio, RSI, periodismo, Transición española, Suiza.

Abstract: The present paper deals with the treatment of Spanish transition to democracy by the Swiss Italian speaking radio (Radio Svizzera di Lingua Italiana-RSI), starting with the regime crisis in October 1975 and ending with the referendum about the constitution's approval in December 1978. The program's duration, structure and participants show a strong interest by swiss radio journalism in the 70s about Spain. 
Through the analysis of five programs one can determine the passionate and constant view of the RSI professionals and the Swiss image of a country in change.

Keywords: radio, RSI, journalism, Spanish transition, Switzerland. 


\section{Introduccion}

Las relaciones entre la España de Franco y la Confederación suiza gozaban durante la Guerra Fría de la máxima cordialidad y de una fuerte estabilidad. Entre los principales ámbitos de interacción de los dos países figuran las relaciones comerciales y financieras, caracterizadas por un importante volumen de capital suizo invertido en la Península. Además, en 1970 la comunidad de emigrantes españoles en Suiza - tema tratado resumidamente en Calvo Salgado (2008) - había alcanzado el número de 113.000 , mientras que ese mismo año el número de viajeros hacia España procedentes de Suiza había superado los 400.000, como recuerda Farré (2006:125 \& 394).

El comienzo del flujo migratorio de España a Suiza a principios de la década de los 60 coincidió con un despertar de reflejos antifranquistas dentro de la izquierda suiza. Los medios de comunicación, como ha sido estudiado por Wilke (2009), se convertirían en principales vectores de las imágenes de España hacia un público helvético. A raíz del movimiento cultural de 1968 se radicalizaría la crítica contra el régimen y contra las buenas relaciones económicas entre ambos países.

\section{Metodología}

Existe ya un gran número de trabajos centrados en diferentes temas alrededor de la percepción extranjera del tardofranquismo o de la Transición española. Cabe mencionar los recientes resultados del proyecto CSO2009-09655 del Plan Nacional I+D+I (2010-2012) realizado por el equipo de Jaume Guillamet (2012) en la Universitat Pompeu Fabra en el que se ha estudiado el papel de la prensa internacional en la cobertura del proceso democratizador. Dentro del marco de este proyecto se analizaron la prensa del Reino Unido, EEUU, Francia, Italia y Alemania occidental. Sobre la percepción en la prensa francesa existen, además, ya diversos artículos de Angoustures -(1990) y (2006)- y de Belmonte (2009). El caso de Italia ha sido ilustrado por Botti (2009). Esta importante serie de trabajos sobre las distintas percepciones de la Transición española en los medios de comunicación extranjeros muestra, sin embargo, dos huecos. El primero es la falta de un estudio sobre la percepción suiza que tenga en cuenta las peculiaridades de este país y la calidad de los enlaces entre Suiza y el régimen de Franco, cuyos principales aspectos han sido anteriormente citados, además de la idiosincrasia helvética, basada en su neutralidad como dogma de su política exterior.

El segundo hueco se debe a la exclusividad de las fuentes utilizadas en dichos trabajos, es decir, la prensa escrita, sin tener en cuenta otros medios de comunicación con un alcance enormemente superior al de los rotativos. Se exceptúa, sin embargo, el 
artículo de Calvo Salgado sobre el programa de radio Galiza sempre, emitido en Ginebra para los emigrantes gallegos (2010). La televisión y la radio son, por tanto, paradójicamente los grandes ausentes en trabajos sobre una época dominada por estos medios. La razón de este abandono ha de buscarse mayoritariamente en la difícil accesibilidad de este material para la investigación, pero también en una reticencia de los historiadores y en la presunta superioridad del texto escrito frente a la imagen o a la palabra oral, como recuerdan Vallotton y Valsangiacomo (2007:41), y en la supuesta escasez de bases teóricas para su tratamiento histórico.

El problema de la accesibilidad está siendo superado, sin embargo, en algunos países gracias a proyectos de conservación, difusión e implementación dentro de la didáctica universitaria y de forma interdisciplinaria. En el caso suizo, la fundación Memoriav, compuesta por diferentes entidades estatales y privadas, se ha propuesto estos mismos objetivos (véase Rauh, 2010: 24-32). El resultado ha sido, entre otras cosas, una base de datos con información sobre material cinematográfico, fotográfico, televisivo, radiofónico y sonoro de Suiza.

Un trabajo basado en material radiofónico responde, por estas razones, a la necesidad de compensar este hueco, aunque el análisis de este recurso se base mayoritariamente en una transcripción del texto oral y deje de lado, por ejemplo, aspectos prosódicos. Los datos publicados en las bases de datos de la Fonoteca Nacional Suiza (FN) ${ }^{1}$ y de Memoriav $^{2}$ resultan muy útiles, pues contienen informaciones fundamentales (como ha señalado Schade, 2007: 57-61) como los nombres de los participantes y la fecha de emisión.

El presente texto pretende, por tanto, operar alrededor de estos dos ejes - la percepción suiza y el enfoque radiofónico. Para evitar una alteración de las fuentes, se renunciará a una traducción de las transcripciones al castellano, prefiriendo mantenerlas en italiano, ya que estos textos son ellos mismos mayoritariamente traducciones de aportaciones en castellano o en otro idioma.

\section{Fuentes}

La Radio Svizzera di Lingua Italiana (RSI) formaba parte, a través de la CORSI (Società cooperativa per la Radiotelevisione svizzera di lingua italiana), de la Sociedad Suiza de Radiodifusión y Televisión (SSR). Esta radio estaba dedicada a abastecer los territorios

\footnotetext{
$1<$ http://www.fonoteca.ch/green/dbAdvancedSearch_en.htm>.

${ }^{2}<$ http://en.memoriav.ch/memobase/default.aspx>.
} 
del Cantón Tesino y aquellos valles de habla italiana en los Grisones con información, cultura y entretenimiento.

Los programas informativos Panorama d'attualità (cast. Panorama de actualidad) y Speciale sera (cast. Especial tarde) pretendían profundizar la información sobre diversos temas de la actualidad política nacional o extranjera. Su uso para la investigación nos permite determinar tanto el interés del periodismo suizo por algunos temas así como las imágenes que los oyentes de los programas pudieron generar. Un enfoque en la RSI responde, por un lado, a un interés por resaltar la labor de una cadena considerada más bien de menor relevancia, comparada con la Radio Suisse Romande (RSR) y la Radio der Deutschen und Rätoromanischen Schweiz (DRS). Por otro lado, justifican este enfoque su relación con su "hermana", la Televisione Svizzera di Lingua Italiana (TSI), donde a partir de 1973 se emitía el informativo para la emigración española Tele-Revista, ya estudiado en Calvo Salgado, Langa Nuño y Prieto López (2012), en el que también se abordaban temas relacionados con el desarrollo político de la España posfranquista.

El material utilizado es accesible tanto a través de la FN en Lugano como del Archivo Federal Suizo (AF) en Berna. Además la FN permite el acceso a estos materiales desde puntos de escucha repartidos por toda Suiza. ${ }^{3}$

\section{Los medios de comunicación suizos en la Guerra Fría}

Antes de adentrarnos en la percepción suiza del tema español, es importante reflejar el contexto de los medios de comunicación suizos durante la Guerra Fría. Desde este punto de vista, la posguerra supuso para Suiza, como también para muchos otros países, una época de desarrollo tecnológico, económico y social sin precedentes. La Guerra Fría trasladaría los campos de batalla reales a aquéllos virtuales, extendidos entre ondas electromagnéticas y papel impreso. Los medios de comunicación se convertirían así en productores de realidades y en armas en la lucha entre dos sistemas de valores completamente opuestos entre sí (Lindenberger, 2006).

El comienzo de la Guerra Fría coincide en Suiza con la renovación de la "Defensa espiritual nacional", movimiento cultural y político iniciado en los años treinta, concebido para fomentar valores considerados típicamente suizos. Tras la derrota del nacionalsocialismo y del fascismo en la Segunda Guerra Mundial, este movimiento se

\footnotetext{
${ }^{3}<$ http://www.fonoteca.ch/green/listeningPlaces_en.htm>.
} 
reajustó para continuar su lucha especialmente contra el comunismo. Para ello se había recurrido a dos importantes medios de comunicación: la radio y el Ciné-Journal Suisse (CJS).

Entre los medios de comunicación existentes en los años cincuenta, la televisión alcanzaría una situación hegemónica frente a la radio pero también a la prensa y al CJS. En Suiza, a diferencia de los regímenes autoritarios de España y Portugal, donde la televisión dependía de un ministerio, o de las repúblicas democráticas de Francia e Italia, donde se habían creado organismos estatales para su regulación y administración, se optó por un modelo de derecho público que garantizase la independencia del estado y que se financiase a través de tasas específicas, modelo al que ya habían adherido los países escandinavos, además de la RFA y de Austria (véase Hickethier, 2010:155).

La introducción de la televisión repercutió negativamente sobre la prensa suiza que empezaba a acusar los primeros síntomas de deterioro. Según Schade (2006a) la desaparición de periódicos está ligada a los propósitos de desregulación del monopolio radiofónico en los años setenta. Numerosos diarios se convirtieron así en semanarios, unos redujeron su tirada, otros desaparecieron completamente o adhirieron a consorcios de prensa. Si bien la desaparición de rotativos preocupase a determinados sectores de la sociedad, el mundo académico prefería hablar con tonos tecnócratas de un fenómeno de "limpieza" necesaria dentro del panorama mediático suizo (Padrutt, 1972: 158).

En los años setenta se establece definitivamente la preponderancia de los medios electromagnéticos que alcanzan su culmen. En 1975 se cuentan 2.075 .574 abonados de radio y 1.759 .116 de televisión, lo cual corresponde a un aumento de respectivamente $1.9 \%$ y $2.6 \%$ frente al año anterior, como se indica en Mäusli y Steigmeier (2006:399).

\section{El papel de la radio en la era de la televisión}

La puesta en servicio de la televisión a principios de los años cincuenta fue acompañada de escepticismo por parte de determinados sectores de la sociedad suiza que desconfiaban del poder del rayo catódico sobre los espectadores y temían un deterioro de la familia bajo su influencia. Otros, en cambio, criticaban la simplificación de los mensajes trasmitidos a través de la televisión. Mientras que esta nueva tecnología gozaba de gran popularidad en la Suiza francófona e italófona, en la parte 
de habla alemana no parecía encontrar las mismas simpatías. En 1956 el gobierno de la Confederación preparó la inserción de un artículo sobre la radio y la televisión en la constitución federal que fue sometido a referéndum en marzo de 1957 y rechazado por los votantes, como recuerda Ehnimb-Bertini (2000:184-185). El artículo pretendía someter la programación de estos medios al control del estado. El lobby de la prensa, por su parte, temía por sus ingresos procedentes de la publicidad y se comprometió a pagar la cifra de dos millones de francos anuales a la SSR a cambio de que ésta renunciase a emitir publicidad (Vallotton, 2006: 38-39).

Los años sesenta suponen una época de importantes modernizaciones tanto para la televisión como para la radio. En 1960 a la "Sociedad Suiza de Radiodifusión" se le agrega "y de Televisión", sin alterar sus siglas. En octubre de 1964, la Confederación otorgó a la SSR una nueva concesión de monopolio. En su artículo 14 se permitía explícitamente por primera vez la inserción limitada de publicidad directa en la televisión. Para la radio, por el contrario, se mantuvo la prohibición. La ausencia de espacio publicitario en la radio permitía un tratamiento más amplio y más profundo de temas de actualidad, es decir, frente a la televisión, donde la duración de las emisiones estaba condicionada por el espacio dedicado a la publicidad, la radio podía mantenerse al margen de razonamientos económicos y optar por un programa basado en la calidad de la información. En 1965, la televisión recaudaría más de 20 millones de francos gracias a la publicidad, como se señala en Mäusli y Steigmeier (2006:399).

El control estatal se reflejaba, además, en el artículo 13 de la concesión que prohibía cualquier emisión cuyo contenido pudiera comprometer la seguridad interior o exterior de la Confederación o de los cantones, su orden constitucional o las relaciones internacionales. Ya en el primer año de su entrada en vigor se aplicaría esta disposición. En 1965 el escritor y periodista Hugo Loetscher no pudo emitir su programa dedicado a la dictadura de Salazar, en el que estaba previsto que recitase su elegía política “Ach, Herr Salazar", como recuerda Vallotton (2006:72).

La televisión había destronado a la radio de su pedestal pero ésta seguía siendo un medio de comunicación muy popular. La competencia entre los dos medios se notaba sobre todo en la programación de la tarde. La llegada de transistores portátiles permitía una escucha radiofónica en cualquier lugar y a cualquier hora, lo cual significaba una clara ventaja respecto a la televisión. Esto explica también el mantenimiento de la prohibición de emitir publicidad en la radio. Para la RSI, como para las demás radios suizas, se plantearon nuevos estilos más conformes a la década de los sesenta. El tono académico y pedante debería dejar su sitio para un estilo más periodístico, desenfadado, ameno y destinado al entretenimiento (Marcacci, 2009:160).

Otra novedad importante supuso también la supresión de la obligación para la radio de emitir los boletines de la Agence Télégraphique Suisse (ATS), permitiendo así a la radio 
su propia redacción de noticias independiente de esta agencia estatal (Schade, 2006b:29 y Vallotton, 2006:54-55). Sin embargo, como hemos visto, las libertades de los profesionales de radio y televisión estaban limitadas por el artículo 13 de la concesión. Si el caso de Loetscher de 1965 es muy significativo para el entendimiento de la política exterior suiza durante la Guerra Fría, no nos ha de sorprender el tono benévolo de otros programas dedicados a la España de Franco. El 25 de abril de 1967 la RSI emitió un programa sobre la situación española. ${ }^{4}$ La recién aprobada Ley Orgánica del Estado como también la libertad de religión fueron los principales temas de dicha emisión pero también se trataron las protestas estudiantiles y las huelgas en Barcelona. Sin embargo, en todo el programa no aparecía en absoluto la palabra "dictadura", utilizándose el término "régimen" una sola vez. Por otro lado, llama la atención el frecuente uso de otras palabras como "referéndum" o "constitución", ésta última como traducción del "Fuero de los españoles", transmitiendo así una imagen distorsionada de la dictadura. La segunda mitad de la emisión empezaba con una alabanza de las buenas relaciones hispano-suizas, para luego centrarse en la solemne celebración del otorgamiento del doctor honoris causa en la Universidad de Alcalá de Henares a dos científicos suizos.

Esta actitud ausente de críticas estaba obviamente condicionada por la normativa en la concesión de 1964. Pero en la radio y en la televisión suizas, las cosas estaban cambiando. La emisión semanal de la televisión de habla alemana Rundschau (cast. "Panorama") del 29 de enero de 1969 comentaba la proclamación del estado de excepción en toda España. En la segunda parte del programa se insertó una entrevista con varios representantes sindicalistas españoles cuyos rostros no fueron captados por la cámara. ${ }^{5}$

Este tipo de programas y entrevistas marcan un cambio de paradigma periodístico que asumiría rasgos muy críticos con las dictaduras y se había estado desarrollando paulatinamente ya a partir de las crisis de la Guerra Fría, como indica Schmidt-Gernig (2002:393). La mirada de la televisión suiza hacia España con motivo del proceso de Burgos en diciembre de 1970 causó la cólera de la Embajada de España (como explicaos en otro lugar, véase Prieto, 2012:9). También la RSI trató el dramático acontecimiento en un programa especial, donde se emitieron entrevistas con exponentes de la oposición (Tierno Galván y Ruiz-Giménez) pero también con el capitán general de Cataluña, para garantizar una información equilibrada. ${ }^{6}$

Las libertades que los profesionales de radio y televisión se tomaban a la hora de emitir sus noticias chocaban a partir de los años setenta cada vez más con las ideas de

\footnotetext{
${ }^{4}$ II microfono della RSI; Spagna d'oggi: Temi d'attualità, 25-4-1967, FN DAT12906.

${ }^{5}$ Rundschau, 29-1-1969, AF J2.225 2007/195 vol. 22.

${ }^{6}$ Panorama d'attualità: La Spagna dopo Burgos, 8-1-1971, AF J2.247 2005/238 vol. 1932.
} 
políticos conservadores. En esta época los medios de comunicación monopolizados sufrían bajo el doble ataque de la derecha que les acusaba de simpatizar con los movimientos contestatarios y de supuestas "infiltraciones comunistas", mientras que la izquierda les echaba en cara una actitud de servilismo frente a la "burguesía" (Vallotton, 2006: 63-69). Con motivo de los últimos fusilamientos en septiembre de 1975 y de la retirada del embajador suizo de su puesto en Madrid, se desató en Suiza una tormenta mediática (Prieto, 2010).

\section{Cinco emisiones sobre España}

\subsection{Un calidoscopio de la oposición antifranquista}

Como se ha comentado anteriormente, la ausencia de publicidad en la radio permitía más libertad a la hora de concebir programas de mayor duración. Por estas razones no sorprende que algunos de estos programas, como el presentado a continuación, superasen la media hora. En el tratamiento del tema de las autonomías y de la independencia de territorios históricos se puede advertir una monopolización temática, pues este sujeto es tratado únicamente desde el punto de vista de Euskadi, sin ninguna mención de las reivindicaciones en Cataluña o en Galicia, exceptuando la intervención del exponente de ETA VI.

El primero de los cinco programas se emitió el 10 de octubre de 1975, es decir, en un momento marcado por las recientes protestas de la diplomacia internacional contra los fusilamientos de dos militantes de ETA y tres del FRAP, el 27 de septiembre. El programa empezaba con un fragmento de una entrevista con el representante del Partido Socialista Popular (PSP) Enrique Tierno Galván, sin traducir:

"El régimen franquista está en su último periodo, en su última etapa. El término "agonía", no sé si es el término que aplicaríamos los españoles, porque realmente, mejor diríamos que es un régimen que está agotado... que está agotado, que no tiene posibilidad de renovación, que no puede sacar de sí mismo posibilidades de futuro."7

Participaron, además de Tierno Galván, y el locutor de radio Graziano Terrani, Joaquín Ruiz-Giménez, el economista Ramón Trías Fargas, el sindicalista Julián Arisa, el jesuita

\footnotetext{
7 Panorama d'attualità; La situazione in Spagna, 10-10-1975, AF J2.247 2005/238 vol. 2094 (ó FN DAT21090).
} 
José Díez Alegría, un párroco anónimo, así como un militante de ETA V y otro de ETA VI.

El moderador presentó a Tierno Galván como abogado y exprofesor de la Universidad de Madrid, expulsado de este ateneo por sus ideas progresistas. Así mismo, el periodista introdujo el contenido del programa, mostrado como una encuesta sobre las fuerzas opositoras a la dictadura y relatado como un viaje por España, que sin embargo empezaba en el País Vasco francés, en Hendaya. "Libérez Garmendia et ses camarades!", eran los gritos de manifestantes antifranquistas que se podían escuchar.

"Garmendia è un militante basco, arrestato dalla polizia spagnola. Si dice che sia morto in carcere. In ogni caso Garmendia è uno dei sei prigionieri a cui il generale Franco ha concesso la grazia nella tragica sentenza del 26 settembre. II giorno dopo, cinque antifranchisti vengono fucilati."

Citando las palabras de un periodista, el moderador exponía la posición europea frente a un problema moral. Europa apoyaría a los hombres que se estaban enfrentando a la dictadura, “¿pero quiénes son estos hombres y qué alternativas ofrecen al régimen?", preguntaba Terrani. Seguidamente se retomaban las palabras de Tierno Galván, ahora traducidas al italiano, en las que exponía los síntomas de la agonía del régimen y enumerando las trabas de la dictadura: la falta de respuestas a la crisis económica; el problema de los regionalismos y el de la burocracia parasitaria que derrocha dinero sin producir nada; los emigrantes españoles, una masa de desamparados y culturalmente no preparados; y el avanzado empobrecimiento de las universidades, ineptas para competir a nivel internacional. Ante la incapacidad del régimen de resolver estos problemas, éste los elude, aseveraba Tierno.

El cambio del modelo personal y autoritario del general Franco hacia una democracia pluralista de tipo occidental era, para Terrani, la ambición del gran número de las fuerzas de la oposición que abarcaba desde la derecha moderada hasta la izquierda radical. Por ello, a continuación, el programa se centró en analizar los dos principales colectivos de la oposición: la Junta Democrática y la Plataforma de Convergencia Democrática. Ruiz-Giménez, líder de ésta última, habló sobre las fuerzas opositoras dentro de su plataforma e hizo hincapié en el aspecto pacífico de la transición que él ambiciona. Ruiz-Giménez explicaba la razón de ser de Convergencia Democrática haciendo referencia a la necesidad de una alianza entre socialistas, socialdemócratas y demócratas cristianos para una democracia pluralista. Aunque la Plataforma había sido creada sin la participación de todas las fuerzas políticas y sociales del país, el objetivo final sería el de una plataforma única que abrazase la totalidad de los colectivos de oposición. Ruiz-Giménez ponía el énfasis en la necesidad de una ruptura democrática rápida. La opinión pública podría resultar útil para la aceleración de este proceso, añade. El político recalcaba el deseo de una democracia pluralista capaz de llevar a cabo las reformas socioeconómicas necesarias, incluyendo algunas nacionalizaciones 
de empresas. Sobre la violencia de grupos antifranquistas, Ruiz-Giménez afirmaba no poder condenar a priori aquéllos que se defienden de las prevaricaciones del régimen, sin antes eliminar las causas que generan esta violencia.

Seguidamente, el programa se centró en el otro colectivo. La Junta Democrática luchaba, en palabras de Tierno Galván, por un régimen democrático consolidado a través de un proceso ordenado. Un pacto entre todas las clases era considerado necesario para resolver los problemas que se estaban viviendo. Así mismo, Tierno Galván negaba rotundamente el supuesto papel dominante del PCE dentro de la Junta Democrática.

A continuación el reportaje enfocó la oposición violenta, es decir, ETA y FRAP. Sobre el FRAP el moderador declaró que sus dirigentes eran desconocidos. Sobre ETA Terrani trató su doble lucha por la democracia y por la autonomía del pueblo vasco, e hizo una descripción en la que recordó el espectacular atentado contra Carrero Blanco, en diciembre de 1973; sus transformaciones durante sus 25 años de existencia; y la ruptura en 1970 que había dado lugar a ETA V y ETA VI. El apoyo de buena parte del pueblo vasco por su labor en favor de sus valores étnicos, culturales y políticos era puesto en relieve por el periodista. Ambas tendencias de ETA estaban en desacuerdo sobre el futuro deseado para Euskadi: para ETA V un estado independiente de España, para ETA VI una región autónoma dentro de una España socialista. Los militantes de las respectivas tendencias expusieron las razones de sus respectivas luchas.

Comisiones Obreras (CC.OO) ocupó el programa a continuación. Su principal estrategia era la huelga que debilitaba la ya delicada economía española, aseveraba Terrani, respondida por el gobierno con la represión para defenderse. Las CC.OO eran presentadas por el sindicalista Julián Arisa, entrevistado por los periodistas de la RSI, que manifestó que los principales objetivos de la organización eran la constitución de un sindicato unitario en una España democrática. Arisa alegaba que no se trataba solamente de reivindicaciones de índole laboral, sino también de una lucha a nivel nacional por la conquista de libertades políticas - de todas las libertades.

Terrani abordaba seguidamente el tema de la economía, refiriéndose a las empresas multinacionales y a la disminución de sus participaciones en España. Se entrevistaba a Ramón Trías Fargas, tildado de tecnócrata liberal, para trazar el desarrollo de la economía española a partir de finales de los años sesenta. El economista dejaba entrever un optimismo moderado para el futuro de la economía hispana, pero añadía que el paso de un régimen autoritario a una democracia no se efectuaría de manera completamente pacífica.

El siguiente apartado del programa estuvo dedicado al papel de la Iglesia, supuestamente deseosa de acelerar la ruptura. Terrani explicó que durante mucho tiempo la iglesia había estado ligada a la dictadura y que, en cierto modo, todavía lo 
seguía estando, pero que el Concilio Vaticano II había creado diferencias entre la institución y el estado español asumidas por parte de la jerarquía eclesiástica. Se entrevistó al jesuita José Díez Alegría y a un párroco que por razones de seguridad permaneció anónimo. Díez Alegría, que contestó en italiano, aludió a la defensa de los intereses de los trabajadores por Acción Católica. También dijo que a raíz del Concilio Vaticano II los obispos habrían adoptado una posición crítica con el régimen que calificó, sin embargo, de "distanciamiento discreto". Por su parte, el sacerdote anónimo, también en italiano, habló sobre las intenciones de renovar el concordato entre el régimen y la Santa Sede. Según él, la omisión de esta renovación sugeriría un comportamiento ambiguo por parte de la iglesia española que intentaría permanecer cerca del pueblo pero sin romper sus lazos con el régimen. A ello añadía Díez Alegría, que la actitud de Tarancón correspondía a la de la Santa Sede, con quien tenía magníficas relaciones. Y confirmó que entre los obispos españoles tan solo una minoría muy reaccionaria conservaría ideas afectas al franquismo de la inmediata posguerra.

Finalmente, el locutor concluyó con alusiones a la intransigente represión por parte del régimen haciendo hincapié en el aislamiento de los intelectuales con el fin de mantener a los españoles en el inmovilismo. Sin embargo, la imagen de una España inmóvil había desparecido, añadía. Si era verdad que el franquismo estaba agonizando, también era verdad que una nueva España empezaba a levantar su voz sin miedo. Como colofón se emitió un fragmento del primer movimiento del Concierto de Aranjuez.

El programa refleja un esfuerzo por ofrecer una información sobre la oposición antifranquista ponderada y equilibrada. La intervención de Tierno Galván, interlocutor muy presente tanto en las emisiones de radio como en la prensa suiza, ofrece un efecto de aceptación general para los oyentes de la RSI y lo mismo vale para la intervención de Ruiz-Giménez.

\section{2 ¿Un franquismo sin Franco? Grandes expectaciones}

Con motivo del empeoramiento de la salud de Franco, la RSI volvería a tratar el tema español nuevamente dentro del formato Panorama d'attualità, $^{8}$ dedicándole media hora a la incierta situación en España. ${ }^{9}$ En el programa participaron el locutor Aldo Sofia, los periodistas italianos Francesco Ricciu, director de la revista italiana Relazioni internazionali y Mario Cervi, corresponsal especial del Giornale Nuovo. Para esta

\footnotetext{
${ }^{8}$ Esta emisión de radio ya ha sido tratada en Prieto López (2012:16-18).

9 La Spagna da Franco a Juan Carlos, Panorama d'attualità, 24-10-1975, AF J2.247 2005/238 vol. 2095 (ó FN DAT21091).
} 
emisión, se recurrió a viejas entrevistas con los opositores Tierno Galván y RuizGiménez, y del mismo Juan Carlos de Borbón. No obstante la falta de un reflejo antiespañol, antimonárquico o antiborbónico en la sociedad suiza, este reportaje expresó un fuerte recelo hacia el príncipe de España y el temor por una continuidad del franquismo bajo una monarquía autoritaria. A pesar de la sensación de inminente desaparición del dictador que la emisión deja entrever, la agonía de Franco duraría casi un mes más.

En este programa se hacía referencia al juramento del príncipe de España ante las Cortes españolas. Tras retrasmitir el discurso sin traducción, ${ }^{10}$ se preguntaban: “¿quién es Juan Carlos y cuáles serían las fuerzas políticas que lo aceptarían o lo rechazarían?". A esta pregunta formulada por Aldo Sofia trataba de contestar Ricciu, haciendo hincapié en la voluntad de instaurar una nueva monarquía bajo la legitimidad del alzamiento del 18 de julio. Seguidamente se insertó una vieja entrevista con Juan Carlos de Borbón en francés. Aldo Sofia precisó que se trataba de una entrevista de hacía unos años, sin revelar su fecha exacta. Las primeras palabras del príncipe respondían a la pregunta sobre su opinión del general Franco:

"Le général Franco est vraiment une figure décisive, historiquement et politiquement, pour l'Espagne. Il a su nous en sortir ou résoudre la notre crise [sic] de 1936. Après ça il a joué politiquement pour nous en sortir de la Deuxième guerre mondiale et, à part ça, pendant ces derniers trente ans, il a mis les bases pour un développement que dans nos jours vous-mêmes pouvez constater."

Personalmente, sobre el general Franco, Juan Carlos de Borbón opinaba:

"Pour moi, c'est un exemple vivant, jour à jour, par son dévouement patriotique envers un service de l'Espagne et à part ça, il est... j'ai pour lui une très grande affection et admiration."

Le siguió una pregunta sobre las ideas monárquicas del pueblo español y sobre sus relaciones con su padre, Juan de Borbón. Aldo Sofia se refirió entonces a la imagen del joven príncipe. Si bien por aquel entonces se le consideraba un partidario de una apertura democrática, su silencio en relación a las ejecuciones lo posicionaría, aparentemente, del lado del autoritarismo y de la represión.

Francesco Ricciu secundó a Aldo Sofia, alegando que durante la manifestación de adhesión al régimen del primero de octubre de ese mismo año, el príncipe de España había aparecido al lado del caudillo. Tanto Cervi como Ricciu ponían el acento en la situación de espera que se estaban viviendo en aquellos momentos. Ricciu consideraba al príncipe Juan Carlos un enigma y sus cualidades muy modestas. En un aspecto

\footnotetext{
${ }^{10}$ Tampoco las aportaciones de Ruiz-Giménez y Tierno Galván fueron traducidas al italiano. Esto se debe probablemente al carácter de urgencia que tenía esta emisión.
} 
fundamental divergieron las opiniones de los dos periodistas. Mientras que Cervi afirmaba que el franquismo moriría con Franco, Ricciu consideraba, en cambio, que el franquismo podría perfectamente tener una continuidad.

\subsection{Entrada en una nueva época}

La emisión especial del 16 de enero de 1976 dedicada a España, y de 20 minutos de duración, abrió con la noticia de la huelga general. ${ }^{11} 300.000$ huelguistas según la versión oficial, medio millón según los adversarios del régimen; unas cifras que el locutor, nuevamente Aldo Sofia, interpretaba como prueba de un verdadero cambio en España. Esta huelga se habría transformado en un movimiento político opuesto al gobierno y a sus "tímidas reformas", alegaba. Tanto la Junta como la Plataforma justifican y apoyan la huelga, decía el locutor, que seguidamente presentaba a los participantes en el programa: Joaquín Ruiz-Giménez; Marcelino Camacho, tildado de "il più prestigioso esponente del sindacalismo democratico spagnolo"; Luís Blanco Villa, periodista del diario católico iYa!; Marco Gandolfi, colaborador de la RSI desde Madrid; además del periodista italiano Francesco Ricciu, desde el mismo estudio radiofónico.

La emisión, comparable con las anteriores en estructura y contenidos, aportó una importante novedad: el testimonio de un representante de la prensa de la derecha que manifestó una fortísima desconfianza frente a los comunistas. Le reacción del locutor Sofia ante la ofensiva verbal de Blanco Villa y su pregunta provocadora con miras a relativizar el discurso anticomunista de su interlocutor mostraron una actitud crítica con determinados sectores de la sociedad española, orientados hacia el pasado y empecinados en identificar el mal con el comunismo.

El programa se centró mayoritariamente alrededor de la pregunta de si la huelga general tenía un carácter estrictamente de reivindicación laboral o si iba más allá. Ricciu habló de la larga preparación de la huelga, durante muchos años de clandestinidad y corriendo muchos riesgos, de la existencia de una conciencia política, negada por el régimen, y del significado político, que iba más allá de las reivindicaciones salariales. Seguidamente se insertó una conferencia telefónica con Gandolfi que informaba desde Madrid y relativizó las reflexiones de Ricciu. El corresponsal afirmó que las manifestaciones no irían más allá de las previsiones de los observadores políticos y que las reivindicaciones tenían un carácter exclusivamente económico al que se habrían añadido peticiones de amnistía y de libertad sindical. Gandolfi comunicaba el propósito del gobierno de convocar nuevas elecciones con un sistema electoral modificado. Para el corresponsal de la RSI esto significaba "un grande

\footnotetext{
${ }^{11}$ Spagna. A due mesi dalla morte del dittatore, 16-1-1976, AF J2.247 2005/39 vol. 3 (ó FN DAT9832).
} 
passo verso l'apertura democratica e forse si può anche dire che sia un grande passo verso la... la democrazia."

Sofia introdujo luego el testimonio del sindicalista Marcelino Camacho. Éste, en francés, explicó la inmediata reacción de los trabajadores españoles e interpretó la lucha sindical como una lucha por el aumento del poder adquisitivo. Sofia le preguntó si estas luchas tenían un carácter exclusivamente material o si poseían también un significado político a lo que contestó que, para defender sus intereses, los obreros debían adoptar una posición de fuerza a través de huelgas pacíficas. Sin embargo, las leyes seguían prohibiendo huelgas, reuniones y manifestaciones, por lo que las reivindicaciones no podían ser meramente económicas. Sin libertad política no podía haber libertad sindical. La tercera y última pregunta para Marcelino Camacho se centró en la negativa del movimiento obrero a aceptar los llamamientos a la estabilidad por parte del gobierno, de lo que podría aprovecharse la derecha. Camacho subrayó entonces el carácter pacífico de las manifestaciones y el deseo de una reconciliación nacional.

Las palabras de Camacho dieron pié para que Francesco Ricciu tildase de inevitable la "explosión" de huelgas y manifestaciones que se vivían en España debido al bajo índice de crecimiento económico de 1975, a la inflación de un 17\%, y al desempleo que alcanzaría el $2 \%$ de la población activa. El aspecto político de las reivindicaciones sería, según Ricciu, todavía más importante que el económico. La reacción de los trabajadores españoles era interpretada como una amonestación para el gobierno de Arias Navarro y Fraga Iribarne.

Consecutivamente, se insertó la entrevista telefónica pregrabada a Ruiz-Giménez que en italiano, declaró su apoyo y solidaridad con las manifestaciones y reconoció la legitimidad de las reivindicaciones obreras.

Aldo Sofia explicó que las aclaraciones de Camacho y Ruiz-Giménez reflejaban las ideas de la oposición democrática respecto a las huelgas y manifestaciones. Ricciu veía en esta lucha una posibilidad para unificar a todas las fuerzas de la oposición antifranquista.

Al periodista Luís Blanco Villa le preguntaron en qué medida se hubiesen podido prever las huelgas y las tensiones sociales. El periodista del diarioiYa!, en italiano, consideró las reivindicaciones de los comunistas españoles principalmente de tipo laboral pero les atribuyó el querer aprovecharse de la debilidad del gobierno para conseguir objetivos políticos. La reacción de Aldo Sofía fue de cierto escepticismo a estas respuestas pues Blanco Villa, en su recelo anticomunista, incluía también a la extrema izquierda. Referente a la actitud del Ejército, el periodista afirmaba:

"L'esercito in Spagna è stato sempre abbastanza tranquillo. Perché veramente in questi quaranta ultimi anni [sic], quarant'anni scorsi, è stato sempre al potere. lo 
direi che in questo momento è anche al potere, questo è chiaro. lo penso, io credo che l'esercito in Spagna resterà fermo e resterà vigilante e non credo, veramente non credo, che in questo momento abbia l'intenzione di intervenire in forma diretta."

Aldo Sofia y Francesco Ricciu comentaron estas palabras. Ricciu estaba de acuerdo con Blanco Villa en lo que concernía a las previsiones sobre el papel del ejército en España. Pero también criticó el tímido programa aperturista de Arias Navarro y Fraga Iribarne y puso énfasis en la necesidad de una verdadera apertura, incluyendo la legalización del PCE. De otra manera -indicaba Ricciu- el gobierno no duraría mucho tiempo, debido a las tensiones que una exclusión de los comunistas de la vida política podrían originar.

\subsection{En vísperas de las primeras elecciones libres}

"Votos afirmativos... 425. Votos negativos... 59. Abstenciones... 13."

"El proyecto de ley ha sido aprobado. Se levanta la sesión. [aplausos]"

La emisión del 13 de junio de 1977, de 26 minutos de duración, empezaba con una referencia a los resultados de la votación en las Cortes franquistas, presididas por Torcuato Fernández Miranda, el 18 de noviembre de 1976, en la que se aprobó el proyecto de Ley de Reforma Política y que posteriormente, en diciembre del mismo año sería aprobado en referéndum por el pueblo español. ${ }^{12}$

El locutor, Luca Giacchetto, presentó la emisión de Speciale sera como un conjunto de opiniones y reflexiones sobre los diferentes partidos políticos de España. En el programa intervinieron a través de entrevistas pregrabadas y en este orden: Fernando Álvarez de Miranda, Jordi Pujol, Pedro de Beitia, ${ }^{13}$ Joaquín Ruiz-Giménez, José María Gil-Robles, Gonzalo Fernández de la Mora, Fernando Morán López y Felipe González. A pesar del gran número de formaciones presentadas, no participó ningún representante de la UCD. De entrada se ensalzaron, sobre todo, las figuras del rey y del presidente del gobierno. Al PSOE, liderado por Felipe González, se le pronosticaron buenos resultados, pero se mostró incertidumbre en lo que concernía los demás partidos.

\footnotetext{
${ }^{12}$ Speciale sera; La Spagna vota. Un Parlamento eletto dal popolo, 13-6-1977, AF J2.247 2005/39 vol. 80 (ó FN DAT9909).

${ }^{13}$ Según la base de datos de la FN y la pronunciación del locutor se trataría de un tal "Pedro Devicia", presentado como exportavoz del gobierno vasco en el exilio y representante del PNV. Por esta razón, es más probable que se trate de Pedro de Beitia, nombre y cargo que aparecen en la edición de $A B C$ del 25 de mayo de 1977, pág. 5. Este tipo de errores en la grafía de nombres es bastante común. Tierno Galván, por ejemplo, aparece en la base de datos como "Tiago Galván”.
} 
El primer político consultado en la emisión fue Fernando Álvarez de Miranda, presidente del Partido Popular Demócrata Cristiano (que un año después se integró en la UCD). Álvarez de Miranda puso de relieve la necesidad de la reforma fiscal, y una política de pleno empleo, es decir, una política de inversiones. Para ello sería necesario, añadía, un compromiso por parte de todos los grupos políticos $y$, en especial, de aquellos más próximos a la clase obrera.

El segundo tema de la emisión fue el de la España de las autonomías y los nacionalismos vasco, catalán, gallego y andaluz. Jordi Pujol, fue presentado como portavoz del Pacte Català, ${ }^{14}$ descrito a su vez como coalición de dos partidos catalanistas definidos como "vagamente socialdemócratas" en el sentido de la República Federal de Alemania.

"[...] La Catalogna è un crogiolo di genti diverse; vogliamo continuare ad esserlo perché è questa la nostra sola possibilità di sopravvivenza. Storicamente siamo sempre stati un'entità europeista. Ci sentiamo molto legati alla tradizione culturale europea, francese e centroeuropea. Abbiamo origini carolingie e per questo la nostra capitale potrebbe essere Aquisgrana, come Bruxelles o come Madrid. L'europeismo potrà certo avere conseguenze negative per la nostra economia, ma pensiamo che se la Spagna non si assocerà all'Europa passeremo momenti terribili."

Manteniendo el tema de las autonomías pero cambiando de región, la emisión reajusta su enfoque hacia Euskadi. Pedro de Beitia, economista y miembro del PNV, mantuvo que su partido participaría en las elecciones, a pesar del secuestro de Javier Ybarra: "Noi, il PSOE, il Partito Comunista dell'Euskadi, le tre centrali sindacali basche andremo alle urne." De Beitia explicó seguidamente la estrategia electoral y las alianzas con el Partido Socialista de Euskadi en las tres provincias vascas y en Navarra.

El siguiente partido presentado fue el PCE por medio de una entrevista con Marcelino Camacho, ante todo sindicalista de CCOO, pero candidato número dos tras Santiago Carrillo en las listas del PCE por Madrid. Camacho expresó la rotunda voluntad de su partido de querer evitar otra guerra civil y negó querer desestabilizar el país en sentido político o económico. A continuación el locutor preguntó si los trabajadores españoles habían tomado conciencia de haber dado el primer paso hacia una democracia. Aunque los comunistas no pretendan desestabilizar la situación económica y política, contestó Camacho, sí estarían dispuestos a dar respuestas concretas y a presionar para negociar y aislar a los elementos ultrafranquistas. Además, el candidato dejó entrever el miedo a un pronunciamiento militar.

${ }^{14}$ Muy probablemente el periodista confunde el Pacte Català, fundado en Hostalric en noviembre de 1976, con el Pacte Democrátic per Catalunya (PDC), alianza compuesta por Esquerra Democràtica de Catalunya, Convergència Democràtica de Catalunya y el Partit Socialista de Catalunya (ex Reagrupament) y liderada por Jordi Pujol i Soley. 
El programa se dedica seguidamente a la presentación de la democracia cristiana, contando con la intervención de Joaquín Ruiz-Giménez, presidente de la Federación Demócrata Cristiana, y de José María Gil-Robles. El locutor comenzó preguntando sobre la negación de Ruiz-Giménez a integrar su coalición dentro de la UCD de Suárez. Ruiz-Giménez, en castellano, razonó que quería mantener una línea genuinamente demócrata-cristiana; el interés por un diálogo con determinados sectores del socialismo; y el estatus de independencia al no participar en el gobierno. Los objetivos de su partido eran un parlamento con poder constituyente, un gobierno que reflejase el resultado de la votación y, en tercer lugar, la solución de los problemas económicos. El locutor profundizó en este último aspecto, para el cual se inserta una intervención de Gil-Robles exponiendo las medidas para el saneamiento de la economía española.

La última parte del programa estuvo dedicada a la presentación de Alianza Popular $(\mathrm{AP})$, nacida a partir de un reagrupamiento de siete ministros de Franco. El locutor mencionó las voces críticas contra este partido:

"Per alcuni, unico scopo di questa intesa [...] è il mantenimento dello status quo. Per questo, i suoi leader sono chiamati di volta in volta "orfani di Franco", "neofranchisti", "esponenti della semi-destra spagnola"."

El partido fue representado en francés por el exministro Gonzalo Fernández de la Mora, autor del libro Crepúsculo de las ideologías. AP fue esbozada como un partido que deseaba conservar y mejorar el patrimonio nacional creado en los últimos cuarenta años. El político subrayó los grandes logros y el desarrollo económico durante esa época. Giacchetto le preguntó por la defensa del sistema electoral mayoritario por parte de AP frente al sistema proporcional a lo que Fernández de la Mora argumentó citando estudios sociológicos y politológicos y aludiendo además a la existencia de este sistema en Francia y en EEUU. La intransigente actitud de rechazo de AP frente al PCE otro punto fundamental de ese partido conservador- era justificada por el exministro a través de referencias a las dictaduras en el Este de Europa y su falta de diálogo y tolerancia. Además, mencionó los casos de Francia e Italia cuyos partidos comunistas se aprovecharon de los derechos políticos para reforzarse sin la creación de un clima de respeto hacia las instituciones democráticas. Fernández de la Mora agudizó su crítica para exponer:

"Ci sono poi motivi storici che sono semplici: Il partito comunista in Spagna e come il nazismo in Europa. È un partito che ha provocato una guerra, che ha perso creando una situazione nazionale tragica. La proibizione del PCE in Spagna è paragonabile alla proibizione del Partito Nazista in Italia, in Germania e in altri paesi."

Sin ningún comentario pero con un breve intermezzo musical de guitarra flamenca, como entre cada presentación de una fuerza política española, el locutor introdujo a 
los socialistas y sus dos principales partidos: el PSOE y el PSP. Es a éste último al que le atribuyó los mayores esfuerzos de oposición socialista durante el régimen. El dirigente del PSP, Fernando Morán López, habló sobre la actitud de su partido frente a la Comunidad Económica Europea y a la OTAN, certificando su vocación claramente europeísta, presente desde su fundación en los años cincuenta, y la necesidad imperativa de un debate sobre la entrada de España en cualquier organización internacional.

Por último participó Felipe González, líder del PSOE, calificado de "hijo de Brandt" por su relación con la socialdemocracia alemana. González se pronunció sobre la situación en España, conceptuándola de peculiar pues la transición se haría a partir de las estructuras del anterior régimen, no como en Portugal.

Llama la atención que la RSI presente por último al PSOE, al ser éste uno de los partidos más importantes y al que se le pronosticaba un gran éxito en aquellas primeras elecciones de 1977 . Este último puesto dentro de la visión conjunta de partidos no sugiere, sin embargo, ningún desprecio por parte de los redactores de la RSI. En una emisión en la cual se ilustran a casi diez organizaciones políticas e intervienen otros tantos interlocutores, el último testimonio se convierte fácilmente en aquél que con más facilidad quedará grabado en la memoria de los oyentes de radio.

\subsection{Una constitución para España}

El programa de la RSI dedicado al referéndum sobre la constitución y emitido el 1 de diciembre de $1978,^{15}$ es decir, días antes del importante acontecimiento, se significa por su duración relativamente breve si se compara con las anteriores: tan solo 12 minutos. Realmente se trató de una entrevista al redactor-jefe de El País que comenzó con una introducción del moderador, Luca Giacchetto, sobre la situación en España. Explicó que aunque la transición había transcurrido sin demasiados traumas violentos, sí se habían producido actos dramáticos como el intento de golpe de estado por parte de nostálgicos del franquismo o las actividades terroristas de ETA.

En entrevista telefónica el periodista Julián García respondió a varias preguntas. La primera cuestión del locutor para García trató sobre la valoración de la fecha del referéndum como punto y final de la dictadura. El español mantuvo que la constitución era absolutamente indispensable para poner fin al periodo dictatorial y que era el principio de una nueva era, aunque no satisficiera a todos los españoles. Además, resaltó la cooperación de varios partidos en la redacción de la magna carta.

\footnotetext{
${ }^{15}$ Speciale sera; Da mercoledì la Spagna diventa una monarchia parlamentare, 1-12-1978, AF J2.247 2005/39 vol. 121 (ó FN DAT9950).
} 
La entrevista tocó el tema del terrorismo de derechas y de izquierda, ya abordado en la introducción de la emisión. Para García la autonomía de Euskadi era absolutamente necesaria y añadió que los vascos habían sufrido la represión franquista más que otros pueblos de España.

"Non penso però che attualmente sia opportuno lottare contro il terrorismo perché non porta a niente. È sempre condannabile, sia quello di estrema sinistra, sia quello di estrema destra. Credo che la legittimità delle rivendicazioni basche non debba essere sostenuta con la violenza. Deve esprimersi attraverso la via pacifica, le urne, nel modo scelto dagli spagnoli per dirigere il futuro del loro paese."

Sobre la persistencia del problema vasco y de la lucha de ETA durante la democracia, el redactor consideró que era un tema muy complicado y divagó sobre la presencia de este fenómeno en países democráticos como el Reino Unido, la RFA e Italia. Del terrorismo de ETA se pasó al del extrema derecha preguntándole sobre las dimensiones reales de amenaza de un golpe de Estado por parte de sectores reaccionarios del Ejército. Para el periodista español el asunto carecía de gravedad: aunque reconocía la existencia de un sector nostálgico, defendía que la mayor parte de los mandos del ejército estaban a favor de la democracia, ensalzando la figura del ministro de defensa, general Gutiérrez Mellado. Sobre si la extrema derecha, como fuerza política, había sido subestimada García hizo referencia a la última manifestación en memoria a la muerte de Franco a la que asistieron entre 200.000 y 250.000 personas, pero relativizó estas cifras alegando que provenían de toda España, aunque resaltó el fanatismo de este colectivo. En las elecciones de 1977 el líder de la extrema derecha Blas Piñar no había conseguido ser elegido senador por Toledo, uno de los baluartes de la extrema derecha, añadió.

El tema de la dimisión de Suárez tras la aprobación de la constitución, gesto exigido en un editorial de El País, fue abordado por Giacchetto que inquirió por qué no disolver el parlamento y convocar de inmediato nuevas elecciones generales. García se mostró partidario de nuevas elecciones pero estimó más urgente la convocatoria a elecciones municipales, pues esos cargos habían sido nombrados bajo el franquismo.

Sobre los dos principales partidos de la oposición, el PSOE y AP, García mantuvo que la lucha entre el PSOE y el gobierno tendría tanto rasgos de estrategia electoral como de ideología. En cambio, en el caso de AP, García expuso las dificultades de este partido situado entre la extrema derecha y el centro, señalando su falta de un electorado fuerte. Sobre el PCE y su actitud pacífica, otro punto de interés de la RSI, y la crisis de los comunistas españoles, García juzgó la política de Carrillo de muy oportuna considerando el momento que se está viviendo en España. 
La pregunta final tuvo como objetivo averiguar qué partido ganaría las elecciones si se convocasen en aquel momento. El periodista contestó que probablemente el espectro político no cambiaría demasiado pero que tanto la UCD como el PSOE ganarían algún escaño. En cambio, tanto AP como el PCE no mejorarían sus presencias en las cámaras, no así la extrema derecha que sí podría entrar con más fuerza en el parlamento. De esta manera finalizó la entrevista.

\section{Conclusiones}

A lo largo de estas cinco emisiones que cubren un lapso de tres años podemos ver que el tema de la democratización española suscitó un interés relativamente grande en la RSI. Como ya se ha dicho, la duración de las emisiones y su compleja composición revelan un enfoque y una motivación que va más allá de la necesidad de información sobre un país cuyos lazos con Suiza eran muy relevantes. El compromiso radiofónico expone no solo interés sino también preocupación por un país en busca de una vía democrática, y también temor por un desenlace traumático.

Este temor se refleja entre otros aspectos en el interés por el papel del ejército y la actitud de los generales frente a las reformas políticas, como también por las manifestaciones y los atentados, como manifiestan las preguntas en la emisión de enero de 1976 y en aquella de diciembre de 1978. Es probable que en este enfoque en las fuerzas armadas influyeran los acontecimientos en Portugal tras la Revolución de los claveles y el papel del ejército en este país.

A pesar del esfuerzo por equilibrar las aportaciones desde el punto de vista ideológico, la emisión deja entrever un estilo periodístico muy progresista y audaz, que no vacila a la hora de entrevistar no solo a comunistas, sino que incluye también a miembros de organizaciones ilegales que recurren a la violencia, e incluso a la derecha nostálgica. Sin embargo, ese equilibrio se evidencia sobre todo a partir de las elecciones de 1977, mientras que anteriormente la radio presentaba principalmente a las organizaciones de la oposición antifranquista y consultaba con frecuencia a los dos máximos exponentes de la oposición moderada, Enrique Tierno Galván y Joaquín Ruiz-Giménez. Además, en junio de 1977 podemos notar un despertar del interés por el PSOE y por su líder Felipe González, interés que continúa en diciembre de 1978.

Otro desarrollo importante se puede notar en la imagen de Juan Carlos de Borbón, inicialmente considerado un mero príncipe franquista, admirador del dictador y con intenciones poco claras, para luego convertirse, junto con Adolfo Suárez, en enérgico protagonista de una transición a la democracia aplaudida por la RSI. 
Las emisiones, compuestas mayoritariamente por entrevistas telefónicas pregrabadas, intervenciones de expertos en el estudio de radio, aportaciones de corresponsales de la RSI y, a veces, por viejas entrevistas, muestran otro aspecto del esfuerzo en la producción del programa - un esfuerzo difícil de cuantificar. A la hora de presentar la compleja realidad española, la redacción de la RSI recurrió a traducciones del castellano o de otros idiomas al italiano, pero también a una traducción con miras a reducir la complejidad de los contenidos españoles para hacerlos comprensibles para un público de habla italiana. A causa de la superposición del relato traducido sobre el relato en lengua original, no es posible averiguar de qué forma se articularon estas dos traducciones.

La información de la RSI sobre España muestra, por tanto, una mirada que se incorpora a la mentalidad periodística transnacional de Europa occidental, es decir, de un espacio cultural que comparte valores e ideas de democracia, parlamentarismo, liberalismo y de estado social, y que también desea una adhesión española a estos valores. A pesar de la hegemonía de la televisión en los años setenta, la RSI, por su condición no comercial, ofrece un documento genuino para la investigación histórica y, en este caso, para la historia transnacional. La radio, en general, es un medio de comunicación que merece más atención por parte de los historiadores cuyos planteamientos deben ir más allá de una mera historia institucional y abordar aquéllos de tipo social y transnacional.

\section{Referencias}

ANGOUSTURES, A. (1990). L'opinion publique française et l'Espagne 1945-75. Revue d'Histoire Moderne \& Contemporaine, 37, 672-686.

ANGOUSTURES, A. (2003). La transition espagnole dans l'opinion française. En A. Dulphy e Y. Léonard (Eds.). De la dictature à la démocratie: voies ibériques (pp. 279-292). Bruxelles: P. Lang.

AZIZ, S.-H. Y PIATTINI, M. (2006). Servizio pubblico o il rispetto delle minoranze. En T. Mäusli y A. Steigmeier (Eds.), Radio und Fernsehen in der Schweiz. Geschichte der Schweizerischen Radio- und Fernsehgesellschaft SRG 1958-1983 (pp. 139-185). Baden: Hier und Jetzt.

BELMONTE, F. (2009). Desde Francia: Miradas a la transición. Los franceses descubren España (noviembre 1975-diciembre 1978). En R. Quirosa-Cheyrouze y Muñoz (Ed.). Prensa y democracia. Los medios de comunicación en la Transición (pp. 263-273). Madrid: Biblioteca Nueva. 
BOTTI, A. (2009). La transición española a la democracia en la prensa italiana. Una primera aproximación. En R. Quirosa-Cheyrouze y Muñoz (Ed.). Prensa y democracia. Los medios de comunicación en la Transición (pp. 275-296). Madrid: Biblioteca Nueva.

CALVO SALGADO, L. M. (2008). “La emigración española en Suiza desde los años sesenta y la primera etapa de las relaciones bilaterales en materia de política migratoria". En J. de la Torre, G. Sanz Lafuente (Eds.), Migraciones y coyuntura económica del franquismo a la democracia (pp. 289-316). Zaragoza: Prensas Universitarias de Zaragoza.

CALVO SALGADO, L. M. (2010). A emigración galega en Suíza e o seus medios de comunicación: o exemplo das emisións de radio de Galiza Sempre. En L. M. Calvo Salgado et al. (Eds.), Galiza en Suiza: aspectos dunha emigración (pp. 19-48). [A Coruña]: Confederación Intersindical Galega.

CALVO SALGADO, L. M., LANGA NUÑO, C. Y PRIETO LÓPEZ, M. (2012). “La Transición española desde la emigración: Tele-revista, revista de actualidad de la televisión pública suiza para los emigrantes españoles". [publicación en línea]. Disponible desde Internet en: <http://ashiscom.org/12congreso/doc/24051101conchalanga-luiscalvo-moisesprieto.pdf $>$ [12-12-2012].

EHNIMB-BERTINI, S. (2000). Jahre des Wachstums: "Die SRG vor neuen Herausforderungen, 1950-1958“. En M. T. Drack (Ed.), Radio und Fernsehen in der Schweiz. Geschichte der Schweizerischen Rundspruchgesellschaft SRG bis 1958 (pp. 153-194). Baden: Hier und Jetzt.

FARRÉ, S. (2006). La Suisse et l'Espagne de Franco. Lausanne: Antipodes.

HICKETHIER, K. (2010). "Europa und die Wirklichkeiten der Fernsehgesellschaft". En U. Daniel y A. Schildt (Eds.), Massenmedien im Europa des 20. Jahrhunderts (pp. 149-174). Köln, Weimar, Wien: Böhlau.

Konzession für die Benützung der elektrischen und radioelektrischen Einrichtungen der Schweizerischen Post-, Telephon- und Telegraphenbetriebe zur öffentlichen Verbreitung von Radio- und Fernsehprogrammen, 24 de octubre de 1964. Feuille Fédérale, vol. 2, n 47, 26 de noviembre de 1964.

LINDENBERGER, T. (2006). Einleitung. En T. Lindenberger (Ed.), Massenmedien im Kalten Krieg. Akteure, Bilder, Resonanzen, (pp. 9-23). Köln, Weimar, Wien: Böhlau.

MÄUSLI, T. Y STEIGMEIER, A. (2006) (Eds.), Radio und Fernsehen in der Schweiz. Geschichte der Schweizerischen Radio- und Fernsehgesellschaft SRG 1958-1983. Baden: Hier und Jetzt. 
MARCACCI, M. (2009). "L'avvento della televisione e il rinnovamento della radio (19621982)". En T. Mäusli (Ed.), Voce e Specchio. Storia della radiotelevisione svizzera di lingua italiana (pp. 121-196). Locarno: Armando Dadò Editore.

PADRUTT, C. (1972). "Zeitung ohne Zukunft?" En C. Padrutt, H. Strehler y H. Zollikofer jun. (Eds.). Die Zeitung auf dem Weg ins Jahr 2000 (pp. 151-172). St. Gallen: Zollikofer \& Co.

GUILLAMET, J. (2012). Presentación de los resultados del proyecto CSO2009-09655 del Plan Nacional I+D+I (2010-2012). [publicación en línea]. Disponible desde Internet en: <http://ashiscom.org/12congreso/doc/niet/24051001-resultadosproyecto.pdf> [23-10-2012].

PRIETO, M. (2010). Militärprozesse und Hinrichtungen des späten Franco-Regimes im Spiegel Schweizer Medien (1970-1975). Schweizerische Zeitschrift für Geschichte, 60, 84-96.

PRIETO LÓPEZ, M. (2012). “La imagen de la monarquía española en las fuentes audiovisuales suizas (1969-1981)". [publicación en línea]. Disponible desde Internet en: <http://ashiscom.org/12congreso/doc/24051108-moisesprieto.pdf $>$ [2-10-2012].

RAUH, F. (2010). Audiovisuelle Mediengeschichte: archivarische und methodische Herausforderungen. Schweizerische Zeitschrift für Geschichte, 60, 23-32.

SCHADE, E. (2006a). "Schweizerische Medienkonzentrationsdebatte in den 1960er bis 1980er Jahren“. En H. Bonfadelli, W. A. Meier y J. Trappel (Eds.), Medienkonzentration Schweiz. Formen, Folgen, Regulierung (pp. 253-278). Bern, Stuttgart, Wien: Paul Haupt.

SCHADE, E. (2006b). "Die SRG auf dem Weg zur forschungsbasierten Programmgestaltung". En T. Mäusli y A. Steigmeier (Eds.), Radio und Fernsehen in der Schweiz. Geschichte der Schweizerischen Radio- und Fernsehgesellschaft SRG 1958-1983 (pp. 293-364). Baden: Hier und Jetzt.

SCHADE, E. (2007). Audio- und Videodokumente als Quellen für die Kommunikationsund Medienforschung. En K. Deggeller, U. Ganz-Blättler y R. Hungerbühler (Eds.), Gehört - Gesehen, Heard - Seen. Das audiovisuelle Erbe und die Wissenschaft. The Uses of Digitised Archives for the Sciences (pp. 49-63). Baden: Hier und Jetzt.

SCHMIDT-GERNIG, A. (2002). Ansichten einer zukünftigen "Weltgesellschaft". Westliche Zukunftsforschung der 60er und 70er Jahre als Beispiel einer transnationalen Expertenöffentlichkeit. En H. Kaelble, M. Kirsch, y A. Schmidt- 
Gernig (Eds.), Transnationale Öffentlichkeiten und Identitäten im 20. Jahrhundert (pp. 393-421). Frankfurt, New York: Campus.

SCHNEIDER, TH. (2006). Vom SRG-“Monopol” zum marktorientierten Rundfunk. En T. Mäusli y A. Steigmeier (Eds.), Radio und Fernsehen in der Schweiz. Geschichte der Schweizerischen Radio- und Fernsehgesellschaft SRG 1958-1983 (pp. 83-137). Baden: Hier und Jetzt.

VALLOTTON, F. (2006). Anastasie ou Cassandre? Le rôle de la radio-télévision dans la société helvétique. En T. Mäusli y A. Steigmeier (Eds.), Radio und Fernsehen in der Schweiz. Geschichte der Schweizerischen Radio- und Fernsehgesellschaft SRG 1958-1983 (pp. 37-82). Baden: Hier und Jetzt.

VALLOTTON, F. Y VALSANGIACOMO, N. (2007). Pour une histoire du sonore: les sources radiophoniques entre recherche et enseignement universitaire. En K. Deggeller, U. Ganz-Blättler y R. Hungerbühler (Eds.), Gehört - Gesehen, Heard Seen. Das audiovisuelle Erbe und die Wissenschaft. The Uses of Digitised Archives for the Sciences (pp. 40-48). Baden: Hier und Jetzt.

VALLOTTON, F. Y VALSANGIACOMO, N. (2010). L'audiovisuel dans l'auditoire. L'intégration des sources radiophoniques et télévisées au sein de l'enseignement académique, Schweizerische Zeitschrift für Geschichte, 60, 33-43.

WILKE, J. (2009). Imagebildung durch Massenmedien. En J. Wilke. Massenmedien und Journalismus in Geschichte und Gegenwart. Gesammelte Studien (pp. 291-300), Bremen: Edition Lumière. 